\title{
Fish-Egg in Eye: Rhinosporidiosis
}

\author{
Gautam Lokdarshi, Bhagabat Nayak*, Neelam Pushker and Seema Kashyap \\ Dr Rajendra Prasad Centre for Ophthalmic Sciences, All India Institute of Medical Sciences, India
}

Submission: March 02, 2017; Published: May 04, 2017

*Corresponding author: Bhagabat Nayak, Dr Rajendra Prasad Centre for Ophthalmic Sciences, All India Institute of Medical Sciences, India, Tel: 011-26593133;Fax: 01126588131; Email: bhagabat80@gmail.com

\section{Summary}

A 9-year-old boy presented with painless, diffused, soft swelling of right lower lid for two and a half months. He used to take baths in the village pond. The swelling was confined to the area over the lacrimal sac. There was broadening of the nose with history of occasional epistaxis. A raised pinkish lesion on the superior bulbar conjunctiva was discovered while examining the right eye. It had a typical "fish-egg" appearance showing multiple white dot lesions present on its surface. Anterior rhinoscopy revealed a nasal polyp filling the right nasal cavity. Microbiological examination of the nasal discharge suggested rhinosporidiosis. He underwent right nasal polypectomy and darcyocystectomy followed by oral Dapsone therapy. The conjunctival lesion disappeared after one month of oral Dapsone therapy.

\section{Introduction}

Ocular rhinosporidiosis may present as a polypoid mass of the palpebral conjunctiva, lacrimal sac diverticulum, recurrent chalazion, chronic follicular conjunctivitis, peripheral keratitis, scleral melting, and as eyelid mass. Lacrimal sac disease may present with blood stained tears.

We report this case because of the typical "fish-egg" appearance as reported in the literature which is not commonly encountered in ophthalmological practice [1]. In addition, resolution of this lesion on oral Dapsone therapy highlights its role as conservative or alternative therapy.

\section{Case Report}

A 9-year-old boy presented with diffuse boggy swelling of the right lower lid, which was noticeable for the last two and a half months. The swelling was painless and there was no associated complaint except for occasional epistaxis. There was history of taking regular bath in the village pond. On examination, he had visual acuity of $6 / 6$ in both the eyes. The swelling was confined below the level of the medial canthal tendon, involving the lacrimal sac area (Figure 1). There was association of broadening of the nose. A slightly raised pinkish lesion was visible on the superior bulbar conjunctiva after retracting right upper lid (Figure 2). The presence of multiple white dots on its surface resembled "fish-egg", a classical clinical sign not commonly observed [1]. The rest of the ocular examination was normal. Anterior rhinoscopy was performed by the ENT surgeon at our centre which revealed a large pinkish polyp filling the right nasal cavity with grey-white spots on its surface along with post-nasal drip.

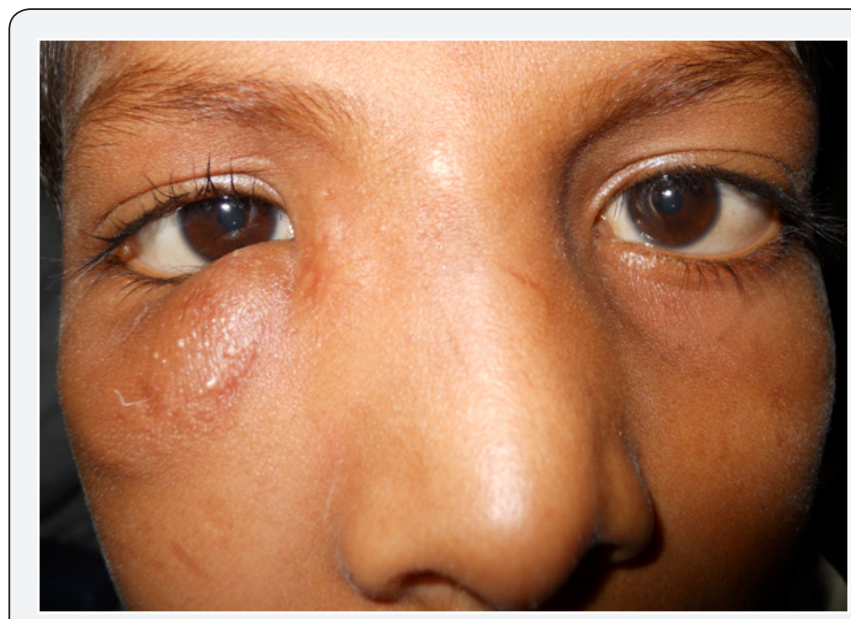

Figure 1: Diffuse "boggy" swelling in right lacrimal sac region associated with broadening of nose.

Microbiology examination of the nasal discharge was performed, which was suggestive of rhinosporidiosis. Computed tomographic-dacryocystography (CT-DCG) revealed patency of the right lacrimal passage in the presence of filling defect in lacrimal sac. Ocular and adnexal squamous papilloma, tubercular conjunctivitis with cold abscess, and allergic rhinoconjunctivitis or chronic rhinosinusitis with nasal polyp were considered as the possible differentials. Presence of white dots and absence of 
geometrically arranged red dots secondary to vascular fronds on the surface of the lesion ruled out squamous papilloma [2]. The absence of ulceration/ irregular border/ fibrinous exudates in the lesion, without regional lymphadenopathy or pulmonary tuberculosis, excludes the second possibility [3]. In the absence of any history of allergy/ atopy, asthma, cystic fibrosis, aspirin, sinusitis or fungal hyphae in nasal smear, likelihood of allergic rhinoconjunctivitis or chronic rhinosinusitis are rare [4].

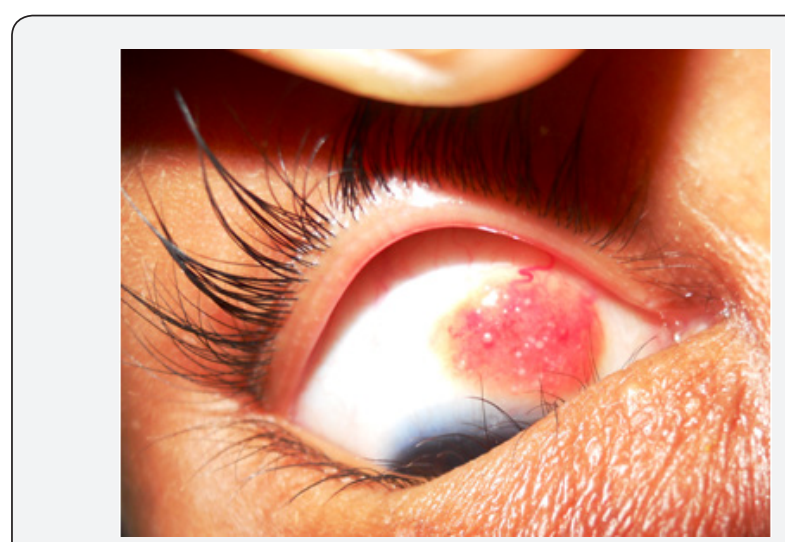

Figure 2: Typical "fish-eggs" like lesion in right bulbar conjunctiva with multiple grey-white lesions over flat pinkish mass.

The boy underwent endoscopic nasal polypectomy and darcyocystectomy under general anesthesia. Histopathological findings of the excised polyp had characteristics of rhinosporidiosis (Figure 3). This was followed by Dapsone therapy at a dose of $50 \mathrm{mg}(2 \mathrm{mg} / \mathrm{kg}$ body weight) orally once daily for three months [5,6]. Liver function test (LFT) and routine haematological investigations had done before starting Dapsone therapy, which were found to be within normal range.

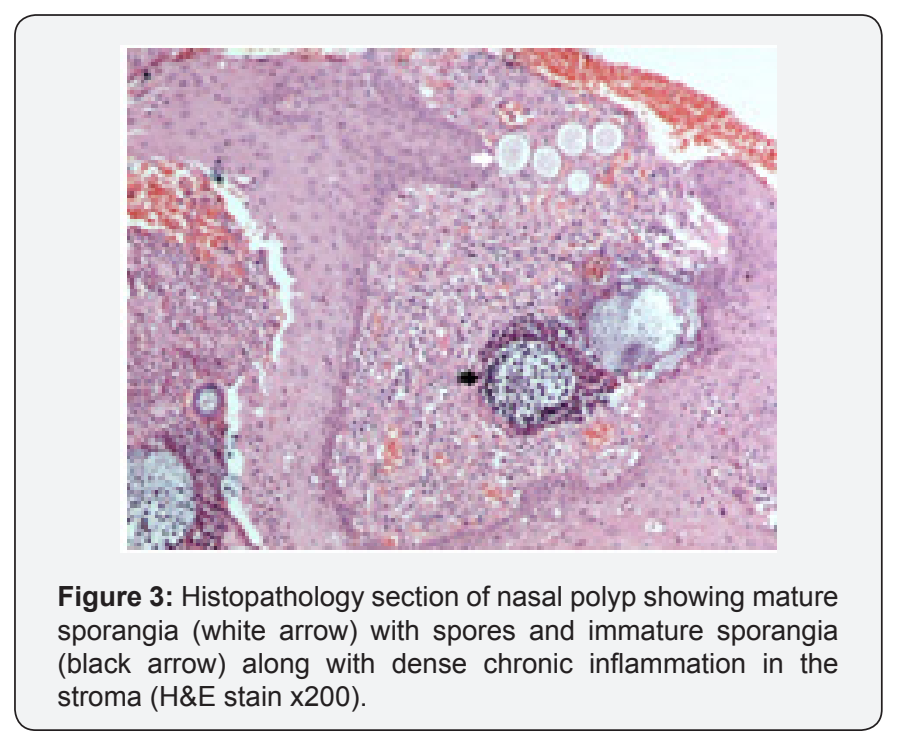

The conjunctival lesion disappeared after one month of Dapsone therapy. Still the drug was continued for another one month. LFT and blood cell counts were within normal range after first and second month of Dapsone therapy. There was no recurrence till the last follow-up up to 6 months.

\section{Discussion}

Rhinosporidiosis is a chronic granulomatous infection of the mucous membranes (nasal, oral, ocular or rectal) caused by Rhinosporidium seeberi. Usually the infection occurs in people who use stagnant water (e.g. lake or pond) for bathing or swimming as was in this case. As most rhinosporidiosis lesions arise from the nose, it is possible that ocular involvement may occur by spreading from the nose through the lacrimal sac to the plica of the conjunctiva. Lacrimal sac disease may present with epiphora or bloody tears, although in our patient there were no such complaints. On literature search we found case reports on conjunctival rhinosporidiosis masquerading as other clinical conditions. Ocular rhinosporidiosis may present as a polypoidal mass of the palpebral conjunctiva, lacrimal sac diverticulum, recurrent chalazion, [7] chronic follicular conjunctivitis, peripheral keratitis, scleral melting or as an eyelid mass. Gichuhi $\mathrm{S}$ et al. [8] reported a case of ocular rhinosporidiosis mimicking as conjunctival papilloma, after vital staining with $0.05 \%$ Toluidine Blue. Leejee $\mathrm{H}$ et al. [9] from Louisiana reported a case of chronic follicular conjunctivitis in a young contact lens wearer. In both the cases, the diagnosis of rhinosporidiosis was confirmed on histopathology examination. Varshney S et al. [10] reported a pediatric case of epiphora, nasal polyp and medial canthal mass, which was found to be lacrimal sac diverticulum due to rhinosporidiosis and was surgically removed. Sood $\mathrm{N}$ et al. [11] reported a case of rhinosporidiosis as a conjunctival polyp, which was surgically removed.

Although most of the conjuctival rhinosporidiosis were reported as polyps, our case had a relatively flat or slightly raised lesion. The grayish white "fish- eggs" were the sporangia of the R.seberi. We insist on the use of oral Dapsone therapy for primary treatment and preventing recurrence of such lesions.

\section{Literature Search}

The authors searched PubMed database and Google Scholar database in January 2016, without language restriction, using the following search terms: Ocular Rhinosporidiosis, Dapsone therapy, Rhinosporidiosis of conjunctiva.

\section{Acknowledgement}

The authors thank the Ocular Pathology Department, Dr. R.P.Centre for Ophthalmic Sciences, AIIMS, New Delhi, for the photo of histopathology section (Figure 3).

\section{References}

1. Kuriakose ET (1963) Oculosporidiosis- Rhinosporidiosis of the Eye. Br J Ophthalmol 47: 346-349.

2. Albert DM, Miller JW, Blodi B, Azar D (2008) Albert and Jakobiec's Principles and Practice in Ophthalmology. ( $3^{\text {rd }}$ edn), Elsevier, London, England, p. 792.

3. Pierson PH (1918) Tuberculosis of the Eye. Cal State J Med 16(2): 7479.

4. Chaaban MR, Walsh EM, Woodworth BA (2013) Epidemiology and 
differential diagnosis of nasal polyps. Am J Rhinol Allergy 27(6): 473478.

5. Job A, Venkateswaran S, Mathan M, Krishnaswami H, Raman R (1993) Medical therapy of rhinosporidiosis with dapsone. J Laryngol Otol 107(9): 809-812.

6. Basu SK, Bain J, Maity K, Chattopadhyay D, Baitalik D, et al. (2016) Rhinosporidiosis of lacrimal sac: An interesting case of orbital swelling. J Nat Sci Biol Med 7(1): 98-101.

7. Mukhopadhyay S, Shome S, Bar PK, Chakrabarti A, Mazumdar S, et al. (2015) Ocular rhinosporidiosis presenting as recurrent chalazion. Int Ophthalmol 35(5): 705-707.
8. Gichuhi S, Onyuma T, Macharia E, et al. (2014) Ocular rhinosporidiosis mimicking conjunctival squamous papilloma in Kenya -a case report. BMC Ophthalmol 14: 45.

9. Suh LH, Barron J, Dubovy SR, Gaunt ML, Ledee DR, et al. (2009) Ocular rhinosporidiosis presenting as chronic follicular conjunctivitis in a contact lens wearer. Arch Ophthalmol 127(8): 1076-1077.

10. Varshney S, Bist SS, Gupta P, Gupta N, Bhatia R (2007) Lacrimal sac diverticulum due to Rhinosporidiosis. Indian J Otolaryngol Head Neck Surg 59(4): 353-356.

11. Sood N, Agarwal MC, Gugnani HC (2012) Ocular rhinosporidiosis: a case report from Delhi. J Infect Dev Ctries 6(11): 825-827.

Your next submission with Juniper Publishers will reach you the below assets

- Quality Editorial service

- Swift Peer Review

- Reprints availability

- E-prints Service

- Manuscript Podcast for convenient understanding

- Global attainment for your research

- Manuscript accessibility in different formats

( Pdf, E-pub, Full Text, Audio)

- Unceasing customer service

Track the below URL for one-step submission https://juniperpublishers.com/online-submission.php 